\title{
Culturas juvenis, identidades e estilo de vida: sentidos do "alternativo" no Baixo Augusta/São Paulo ${ }^{1}$
}

\section{Youth cultures, identities and lifestyle: meanings of the "alternative" in Baixo Augusta/São Paulo}

Simone Luci Pereira ${ }^{2}$

Vitor Pontes ${ }^{3}$

Resumo: Apresentamos neste artigo aspectos da pesquisa que vem sendo realizada sobre a construção de identidades ligadas a um "ethos alternativo" entre jovens frequentadores da região do Baixo Augusta em São Paulo. Articulando práticas de consumo (em suas lógicas de produção e recepção), cenas musicais, moda e estilos de vida, buscamos compreender estas experiências e imaginários juvenis (por meio de etnografia) que compõem identidades e formas de consumir alternativas ao mainstream e à cultura hegemônica. Com isso, reposicionam-se e ressemantizam-se noções de resistência juvenil que se esboçam não apenas pelo enfrentamento mas por negociações entre as lógicas dominantes e as astúcias cotidianas, perfazendo-se em ações de teor político, estético e performativo.

Palavras-chave: alternativo; culturas juvenis; estilo de vida; consumo; Baixo Augusta

Abstract: We present in this article aspects of the research that has been carried out on processes of identity construction linked to an "alternative ethos" among young people in Baixo Augusta region in São Paulo. Articulating consumer practices (in their production and reception logics), music scenes, fashion and lifestyles, we seek to understand these juvenile experiences and imaginaries

1 Uma versão reduzida deste artigo foi apresentada no GT "Comunicação, consumo e novos fluxos políticos: ativismos, cosmopolitismos, práticas contra-hegemônicas”, no COMUNICON 2016.

2 Universidade Paulista - UNIP. São Paulo, SP, Brasil. E-mail: simonelp@uol.com.br

3 Universidade Paulista - UNIP. São Paulo, SP, Brasil. E-mail: e.vitorpontes@outllok.com 
(through ethnography) that build identities and ways of consuming alternatives to mainstream and to hegemonic culture. Thus, notions of youth resistance are re-established and resemantized, which are outlined not only by confrontation, but by negotiations between the dominant logics and everyday astuteness, demonstrated in political, aesthetic and performative actions.

Keywords: alternative; youth cultures; lifestyle; consumption; Baixo Augusta 
As contribuições advindas dos debates sobre culturas urbanas, práticas de consumo, juventudes e estilos de vida auxiliam na compreensão sobre as identidades juvenis que se fazem e refazem nas cidades, onde territorialidades se constroem em torno de práticas cotidianas, estilos de vida distintivos, usos dos espaços urbanos e formas de consumir.

Se num certo período (décadas de 1970 até meados da década de 1980) a discussão em torno destes eixos se concentrava em noções de subculturas, resistência e contra hegemonia, enfatizando questões de classe e raça (HEBDIGE, 2004; HALL; JEFFERSON, 1993), a partir dos anos 1990 este debate foi incorporando o consumo (em seus aspectos materiais e simbólicos) como elemento fundamental para a compreensão das culturas juvenis, bem como as modas, estilos e territorialidades urbanas envolvidas nas práticas musicais coadunadas no conceito de cena (STRAW, 1991), reposicionando as noções de resistência (FREIRE FILHO, 2005, 2007) que entram em jogo quando tratamos de refletir sobre juventudes urbanas em suas formas de agir cotidianas inseridas na cultura midiática e de consumo. Outros sentidos de resistência, assim, passam a ganhar luzes e serem analisados, ampliando o escopo para pensar não apenas as formas diretas e explícitas de enfrentamento ao mainstream ou hegemônico, mas as formas sutis e negociadas que conjugam lógicas diversas e contraditórias de incorporação e rechaço.

Este artigo apresenta aspectos da pesquisa que vem sendo realizada no Baixo Augusta ${ }^{4}$ (São Paulo/SP) na qual priorizamos aspectos de uma "cultura alternativa" ou um "ethos alternativo" que se mostra uma das principais características de parte dos frequentadores desta região da cidade aqui investigada. Compreender os sentidos deste "alternativo" é o objetivo central deste texto, que apresenta também uma discussão teórico-conceitual sobre juventudes, estilos de vida e práticas de consumo,

4 Parte da rua Augusta localizada entre o cruzamento com a Avenida Paulista e o centro da cidade. Esta área é assim reconhecida pelos seus frequentadores e moradores como diferenciada de outras partes da mesma rua, em que a ênfase recai sobre seu caráter boêmio, juvenil, alternativo, underground. Utilizamos na pesquisa a noção de territorialidade (HAESBERT, 2002) para abordar esta área da cidade. 
bem como dados da etnografia que vem sendo realizada no ambiente noturno do Baixo Augusta.

A investigação caminha por três principais eixos que ajudam a elucidar e compreender como se articula essa "cultura alternativa" nesta localidade. Um primeiro é a moda, que abrange as indumentárias, seus usos e apropriações de diferentes estilos, mesclando-os e/ou ressignificando objetos, conceitos e tendências nos vestuários, acessórios, penteados e demais símbolos que ajudam a construir identidades presentes nesses grupos. O segundo eixo gira em torno das cenas (JANOTTI; SÁ, 2013) e circuitos musicais (HERSCHMANN, 2013), que se mostram como outro elemento fundante ajudando a definir os estilos e pertencimentos destes grupos, podendo apresentar mesclas, confluências e conflitos entre variados gêneros musicais. Esse eixo também se faz importante ao analisar como a música pode ser capaz de agrupar (ou segmentar) grupos de pessoas que escutam e consomem um mesmo gênero/estilo musical, sendo um forte referencial que ajuda a definir estilos, gostos, alianças e identidades, articulando-se às roupas, atitudes, lugares frequentados.

O terceiro eixo que aglutina os dois primeiros baseia-se na noção de "estilo de vida" (GIDDENS, 2002; FEATHERSTONE, 1995), dizendo respeito às escolhas que indivíduos e grupos devem realizar frente à variedade de possibilidades abertas pela (Pós-)Modernidade ligadas ao consumo e à constituição de auto identidade. Junte-se a isso a noção de distinção (BOURDIEU, 2007) que garante capital simbólico e se mostra como um aspecto importante ao pensarmos nesses grupos que constituem o Baixo Augusta por ser aquilo que constitui as características que outorgam prestigio e diferenciação dos demais no ambiente social. Nesta intrincada construção de identidades ligadas ao consumo de roupas, acessórios e música em cenas e circuitos específicos é que vamos percebendo a conformação de um jeito de ser e viver ou de um "ethos-alternativo" que vai se delineando na confluência de variados estilos de vida, como também em formas de resistir à cultura mainsntream ao mesmo tempo em que incorpora elementos dela outorgando-lhe outros usos, numa astúcia e negociação que exploraremos mais a frente. Ainda 
que tenhamos como foco central analisar as indumentárias e o consumo musical destes jovens, estamos compreendendo este "ethos alternativo" como algo mais amplo que incorpora maneiras de consumir (alimentação, informação, lazer, etc.), posturas políticas e comportamentais que se querem alternativas ao hegemônico e normativo.

Lembramos ainda que, junto à noção de estilo e vida e distinção que incidem neste "ethos alternativo" investigado, está aquilo que Feixa (1996) conceitua como "culturas juvenis", ou seja, a maneira com que as experiências sociais dos jovens são expressas coletivamente mediante a construção de estilos de vida distintivos, localizados fundamentalmente no tempo livre ou em espaços intersticiais da vida institucional, colocando no centro do debate questões de identidade, vida cotidiana e protagonismos destes atores. Acrescentamos ainda que as noções de juventude e culturas juvenis devem ser pensadas levando em conta o caráter fluido e permeável dos grupos, nos quais ressaltam-se a diversidade e a pluralidade das experiências sociais.

Buscamos compreender a articulação existente entre estes três eixos (moda, cenas/circuitos musicais e estilos de vida) na cultura juvenil não encarados de maneira separada ou autônoma, mas em seus processos de articulação e conflito que conformam este "ethos alternativo" em seus modos de experimentar a cidade e a cultura do consumo (material e simbolicamente).

\section{Subculturais, resistentes, alternativos}

Bastos (2016) discute a Rua Augusta como polo referencial urbano analisando a construção de seu imaginário para moradores e frequentadores e as mútuas influências entre os sujeitos e o imaginário da Rua Augusta: consumir referências vindas da Rua Augusta retroalimenta o imaginário sobre esta localidade urbana. A autora percebe a presença expressiva dos signos e das materialidades relacionada ao vintage e ao retrô como sendo algo explorado pela cultura de massas para suprir uma carência existencial da representatividade do imaginário "alternativo". 
Embora reconheçamos que, de fato, haja estratégias do mercado de moda, gastronômico e musical em se alimentar deste desejo de distinção que se faz presente nas lógicas das culturas juvenis e urbanas na atualidade, postulamos uma compreensão destas práticas culturais e de consumo a contrapelo. Ou seja, sem desconsiderar as lógicas de produção estratégicas na formação de nichos de mercado fora da cultura de massas, buscamos compreender as maneiras de apropriação que jovens frequentadores deste universo elaboram na lógica dos usos, ressignificando muitas vezes os elementos lançados desde cima. Nesta lógica dos usos, vão se esboçando identidades e estilos de vida fora dos padrões do mainstream e da cultura hegemônica massiva, criando hábitos de consumo cultural e material não hegemônicos que se querem "alternativos". Estes hábitos contemplam consumo, maneiras de usar a cidade, formas de socialidades e estéticas diversificadas, criadas ou apropriadas por esses frequentadores da vida noturna do Baixo Augusta. Ao pensar as modas, músicas/cenas musicais e estilos de vida destes grupos vem sendo possível perceber a existência de uma diversidade que permite um fluxo constante de trocas e mesclas entre referenciais variados. Obviamente não ignoramos a ação de um mercado que se modifica e se adequa constantemente para atender aos desejos aí presentes. No entanto, existem formas de negociação, em que estes jovens vão se apropriando de produtos, serviços e imaginários oferecidos por esse mercado por meio de diferentes usos.

Guiamo-nos aqui pela perspectiva gramsciana de cultura como campo de luta, disputas, apropriações e negociações presentes nas considerações dos Estudos Culturais Britânicos (ESCOSTEGUY, 2001). Tal conceituação nos ajuda a perceber e analisar as negociações conflituosas existentes entre os diferentes grupos sociais e a cultura hegemônica/ mainstream. Nesta noção de negociação se reposicionam ou se re-semantizam noções de resistência cultural vistas como algo autônomo ou como puro enfrentamento ao hegemônico para dar espaço a uma noção de resistência que se faz nas fímbrias, no cotidiano, nas apropriações 
inesperadas e não programadas dos grupos juvenis frente às lógicas de produção, como temos percebido entre os jovens analisados.

Freire Filho (2007) compreende o conceito de resistência em sua dinâmica histórica e na busca por refletir sobre as formas com que esta noção pode ser pensada quando tratamos de grupos culturais juvenis. Como conceito camaleônico, para a tradição dos Estudos Culturais britânicos resistir significava a contestação frontal e explícita da classe trabalhadora jovem inglesa (como os punks) ou de outras formações subculturais contra hegemônicas; já para os estudos pós-subculturais juvenis (FREIRE FILHO, 2005), a noção de resistência se ampliou para incorporar formas de negociação das identidades ligadas às culturas do consumo. Uma noção de resistência, assim, que consegue dar conta da volatilidade de estilos, modas e identidades, como também das sensibilidades e a multiplicidade de referências envolvidas nas práticas juvenis, reavaliando a relação entre jovens, música, moda, estilo de vida, identidade e mídias.

As noções certeaunianas de táticas e estratégias (CERTEAU, 1994) mostram-se úteis para a análise de processos culturais e lógicas de consumo. Como planejamentos e adequações esquematizadas pelo/no mercado e/ou instituições sociais, as estratégias mostram-se como ações racionais para os que detêm o poder. As táticas, por sua vez, são as astúcias cotidianas dos grupos sociais e de indivíduos que burlam o que lhes é imposto de maneira sub-reptícia e subliminar. As relações entre os grupos juvenis do Baixo Augusta analisados e o mercado que os atende é uma negociação constante entre estratégias mercadológicas que tentam enquadrar esses grupos em um nicho de mercado e os usos e táticas criadas por estes grupos para burlar, subverter ou resistir a esse sistema, criando constantemente novas tendências a serem explorados pelo mercado, dando diferentes usos e apropriando-se de diferentes formas. Conjugam-se aí lógicas diversas de incorporações, seduções e variadas formas de resistência, sem reduzir estas práticas a oposições dicotômicas de "integração" ou "confrontação". 
Esse constante conflito é o que proporciona negociações que compõem esse cenário do Baixo Augusta na moda, na música/cena musical, no estilo de vida desses grupos juvenis, estando presente nos produtos e serviços oferecidos por esse mercado em constante mudança: nos bares, restaurantes, food trucks, casas noturnas/baladas, lojas/galerias de roupas, acessórios, artigos de decoração e design, salões de beleza, entre tantos outros possíveis segmentos que o mercado do Baixo Augusta proporciona a quem o frequenta.

Neste sentido, aliado ao conceito bourdiano de distinção, a noção de onivorismo cultural (PETERSON; KERN, 1996) nos auxilia na compreensão de práticas de consumo juvenil no Baixo Augusta. Este onivorismo se refere a um ecletismo dos gostos articulado a lógicas culturais globais que valorizam gostos e consumo do que é exótico e diferente (e não apenas do que é considerado clássico nos padrões ocidentais), numa assimilação do novo e da diferença que vai ganhando espaço e legitimação.

\section{Um ethos alternativo?}

O debate sobre o "alternativo" na cultura e nos meios de comunicação tem em seu histórico as discussões sobre imprensa e comunicação "alternativa" nos anos 1970, quando era sinônimo de "popular", "engajado", "comunitário", "independente". No contexto ditatorial vivido pelo Brasil naquele momento o alternativo ganhava fortes cores de autonomia e de contestação ao status quo, mostrando-se como canal de expressão info-comunicativo frente aos grupos midiáticos hegemônicos comerciais ou estatais e às instituições em geral. Com a redemocratização do país, já na segunda metade dos anos 1980, o "alternativo" ligado à comunicação vai se objetivando em comunitário, ligado a movimentos sociais, ONGs, radio-escolas, imprensa universitária, etc. (PERUZZO, 2008).

No entanto, a noção de "alternativo" que aqui trabalhamos a partir do grupo estudado trata de estilos de vida e consumo que se querem alternativos como uma possibilidade de ser um outro - sugerido pela própria etimologia da palavra. Nesta perspectiva, uma ética alternativa 
de vida se daria, como temos observado, no consumo consciente e crítico, em maneiras de atuar nas bordas do mainstream massificador na moda e nos gostos musicais, em formas mais tolerantes e inclusivas nos comportamentos. Enfim, uma noção de invenção e performatividade das identidades nas culturas juvenis.

Um jeito de ser e viver alternativo, no entanto, que não necessariamente se coloca totalmente autônomo e independente das mídias e das lógicas de produção mercadológicas massivas, mas que negocia e elabora o seu "ethos" nas fímbrias e nos subtextos cotidianos. Levamos em conta aqui o prestígio que o minoritário e o exclusivo outorgam a quem os consome, algo que faz parte das dinâmicas presentes nas subculturas juvenis ligadas ao estético e performativo na moda e na música (THORNTON, 1995). Outro aspecto a ser considerado, ao menos no que tange à música e às cenas musicais contemporâneas é que, se até os anos 1990 era mais fácil perceber uma nítida separação entre majors e indies, esta separação não é tão clara hoje, havendo uma grande rede capilar que envolve diferentemente aos grandes e aos pequenos produtores e músicos (HERSCHMANN, 2011). A noção de "alternativo" (PEREIRA; BORELLI, 2015), assim, surge como nomeação para estas práticas midiáticas, culturais e de consumo que envolvem as culturas juvenis contemporâneas feitas da negociação e presentes nas identidades que os jovens analisados frequentadores do Baixo Augusta parecem assumir.

Dessa forma, o "alternativo" é assumido aqui como um conceito "sob rasura”, tal qual nos sugere Stuart Hall (2000) ao pensar identidades. "Sob rasura" é uma denominação dada a um processo que se mantem sempre em construção ou reestruturação, sem torna-lo estático. Assumimos este "alternativo" como algo contingencial e sempre relacional, não possuindo os mesmos sentidos em qualquer grupo analisado. Hall (2000) pensa a identidade em um processo de fluidez constante e, assim como o autor, enxergamos este "ethos alternativo" como forma de representação dinâmica que se mantem como "ponto de sutura" (HALL, 2000) entre elementos hegemônicos em negociação com formas outras de consumir e experimentar a cultura. Um "alternativo", assim, que 
passa a ser uma manifestação cultural articulando estilos de vida distintivos que constroem suas identidades de maneira seletiva e arquitetada, trazendo múltiplas formas de socialidades e maneiras de ser e viver construídas por esses grupos juvenis.

Sendo as identidades um "ponto de sutura" e em negociação constante entre elementos normativos, institucionais e hegemônicos em conflito e costura com formas mais inventivas de ser, estetizar-se e subjetivar-se, mostra-se tarefa complexa e de importante compreensão a elaboração e articulação das identidades juvenis no Baixo Augusta, uma vez que seus contornos não são uniformes e mostram-se muito dinâmicos, sempre em mudança e rearranjo de posições. Percebemos ali uma constante busca por construir um imaginário identitário "alternativo"; um imaginário que se quer não hegemônico, minoritário, não massivo, mas que dialoga com símbolos e estéticas da cultura hegemônica e mercadológica 5 .

Ao compreendê-los como "alternativos" buscamos refletir sobre os sentidos desta nomenclatura no Baixo Augusta em múltiplas formas de resistências táticas em negociação com elementos mainstream e não apenas pelo puro enfrentamento. E mais, salientamos aqui sentidos políticos de tais ações e imaginários "alternativos" seja nas formas de se apropriar e experimentar a cidade, seja no uso astucioso dos elementos da moda e da cultura de massas, seja criando estilos de vida em que corporalidades e socialidades outras se articulam. Um alternativo, assim, que se perfaz na negociação e construindo formas não hegemônicas (e não necessariamente contra hegemônicas) de consumir, viver e socializar. Um desafio analítico, desta forma, ao perceber que o alternativo não está totalmente desvinculado do mercadológico e institucional, mas dialoga e negocia com estes elementos dando-lhes outros sentidos.

5 Percebemos isso, por exemplo, nas casas noturnas analisadas mais amplamente nesta pesquisa: o Espaço Desmanche, o Inferno Club e o Beco 203. Nestas, há em comum uma mescla de elementos da cultura pop e até massiva com símbolos e sonoridades ligados ao kitsch, exótico ou underground, numa negociação de referências, estilos e identidades expressas nas festas, indumentárias dos frequentadores e gêneros musicais executados por grupos ao vivo ou por DJs. 


\section{Nas ruas do Baixo Augusta}

A pesquisa de campo de base etnográfica realizada envolveu observação participante e conversas com frequentadores e pessoas que trabalham na área do Baixo Augusta. Tivemos como enfoque a vida noturna da região, seus principais circuitos de práticas musicais alternativas, bares, restaurantes, baladas, casas noturnas, galerias, lojas e o fluxo nas calçadas, buscando articular as possíveis relações existentes entre seus hábitos de consumo de moda, música, de alimentação a um certo "ethos alternativo" que buscamos interpretar.

Magnani (2002) considera a Antropologia urbana um campo de pesquisa direcionado para o estudo de grupos sociais presentes nos circuitos dos centros urbanos e suas práticas, numa aproximação à complexidade destas dinâmicas. Uma investigação em que se busca interpretar "por dentro" a realidade de um grupo, tentando acessar os valores, marcas simbólicas, sistemas classificatórios e distintivos, gostos, hábitos, visão de mundo, sentidos de pertencimento e o modo como isto é vivido no cotidiano. Assim, uma das áreas de pesquisa que se adequa e se mostra mais importante na antropologia urbana, é o estudo de bairros, ruas, localidades, regiões e áreas da cidade, onde se dão as socialidades dos grupos urbanos (VELHO, 2009). Em diálogo com este campo de estudos é que temos como método uma análise das práticas de socialidade e construção de identidades dos grupos aqui analisados.

Lembramos, entretanto, que esta pesquisa foi de observação participante com um olhar e uma escuta engajadas na percepção do campo e em conversas livres com frequentadores da região, sem a realização de entrevistas formais. Nunes (2016) sugere a flânerie como metodologia (inspirada nas proposições de Peter McLaren) e o flâneur como etnógrafo pós-moderno que, fugindo de categorias fixas de análise, mergulha na cidade movimentada e dinâmica na busca por "capturar narrativas por meio da leitura das conformações humanas e espaciais, fixando-as mais livremente em atos de escrita, seguindo o engajamento narrativo" (NUNES, 2016, p. 145). Esta proposta metodológica nos pareceu bastante adequada para capturar esses indícios e sinais de um estilo de 
vida alternativo que tentamos interpretar em culturas juvenis urbanas dinâmicas e sem contornos tão específicos ou neotribais. Sem uma delimitação prévia do número de entrevistados ou mesmo de um roteiro estruturado de perguntas, seguimos nas ruas, lojas, bares e casas noturnas os fluxos e energias "sensuais do espaço e das configurações subjetivas" (NUNES, 2016, p.145), atentos aos gestos, indumentárias, atitudes, narrativas e performatividades que se apresentavam nestes espaços.

Além desses principais circuitos da noite do Baixo Augusta, outros espaços da região se mostram importantes por concentrarem este espírito das ruas, em formas de socialidade dinâmicas e múltiplas: a calçada do Shopping Center 3 e as calçadas da Rua Peixoto Gomide; o Espaço Itaú de Cinema e as barracas de camelôs com filmes alternativos pirateados; as galerias Village, De Tudo um Pouco e o Espaço Endossa; o Calçadão Urbanoide de food truck; os restaurantes que vão da culinária gourmet e de diferentes nacionalidades, até a típica "casa do norte" tradicionalmente nordestina.

As incursões de pesquisa no Baixo Augusta se deram entre os anos de 2015 até início de 2017, na maioria das vezes no período da noite/ madrugada, sempre nos finais de semana (geralmente sextas-feiras e sábados), que são os dias em que se tem um maior fluxo de pessoas na área. Como um dos principais eixos da pesquisa tratou do mapeamento dos variados circuitos/cenas musicais que compõem a região, tivemos como foco a percepção da paisagem sonora que se constitui dos sons que se fazem presentes e ecoam num dado ambiente. A paisagem sonora torna-se algo a ser sensorialmente percebido, contemplando todo e qualquer som/ruído que componha uma espécie de "orquestra urbana" (que não se quer harmoniosa, mas sim dissonante e conflitiva) formada por toda manifestação audível. Assim, o objetivo foi caminhar pelas calçadas e perceber as diferentes referências sonoras para além da música, incorporando os sons do ambiente e aquilo tantas vezes identificado como ruído.

Uma das principais características que se pôde observar/escutar, pensando a sonoridade presente ao caminhar pelo Baixo Augusta e suas 
imediações era a mudança constante de gêneros musicais. Ao caminhar de uma calçada até outra, o rock que se ouvia passava a ser música de fundo de um funk que então predominava naquele espaço; e seguindo caminhando, a música predominante ali já não é era mais o funk, mas sim um indie. Os sons surgiam de diferentes fontes: ora de um bar, ora da entrada de uma balada, ora de um carro que passa, ora do celular de um grupo de pessoas que faz uso do aparelho para cantar junto ou apenas se divertir e socializar no meio da calçada.

Ao pensar o espaço como um território urbano delimitado simbolicamente para além de sua existência material, temos a presença de um circuito constituído por diversos elementos que transmitem sentidos, podendo ser lidos e interpretados de diversas maneiras. Os processos de territorialização e reterritorialização (ROLNIK, 1992; HAESBERT, 2002) do meio urbano em meio à vida cotidiana dos grupos que frequentam o ambiente em questão passam a ser elemento importante na compreensão dos usos do espaço - tornado território apropriado e vivido - articulado às identidades e estilos de vida que o consumo material e simbólico engendram. Desse modo, o território que contempla as imediações do Baixo Augusta em suas diversas referências culturais em coexistência, passa a compor um mosaico de sobreposições e entrecruzamentos que concebem identidades múltiplas/hibridas em confluência e conflito.

Além desses aspectos, a sonoridade que ecoa nas ruas da região, muitas vezes surpreende, nos levando a diferentes épocas através dos sons encontrados em casas noturnas especializadas em um especifico tipo de música, como por exemplo, o rock clássico que já não é um gênero musical que está presente nos meios massivos. Essa característica do Baixo Augusta de mesclar temporalidades diversas, está presente também nas roupas/estilos das pessoas que ali frequentam, quanto nos objetos que adornam os vários ambientes das lojas/galerias, bares, baladas, entre outros.

As diversas temporalidades existentes em cada formação cultural propostas por Williams (1979) se fazem presentes aqui. Dominante, 
residual e emergente surgem como elementos temporais em luta por hegemonia e numa constante dinâmica no interior dos circuitos culturais como os que aqui analisamos. Segundo Williams, entre os elementos residuais verificamos aqueles elementos do passado, reconhecidos como antigos, mas que ainda se fazem presentes na atualidade; entre os emergentes temos aquilo que é novo ou potencialmente novo numa cultura, apontando para formas, valores, estéticas inovadoras ou até contra hegemônicas; e entre os dominantes temos aquilo que é hegemônico numa cultura em elementos com forte predominância. Estes três elementos se acham em constante dinâmica e luta por espaço, trazendo o componente diacrônico da cultura e trocando as posições de dominância a todo momento. Nesta fluidez que articula elementos da cultura de massas e hegemônica até aqueles mais inovadores e fora dos padrões (na moda, no estilo de vida ou nas cenas musicais) vai se compondo este "ethos-alternativo" entre grupos juvenis no Baixo Augusta.

Na moda e na música presente na região, há muitas influências do vintage e do retrô, mescladas com elementos atuais que aludem a um consumo do passado e a uma sedução pelo antigo em grupos juvenis contemporâneos como indicio de um certo regime de temporalidade presentista e nostálgico (PEREIRA; BORELLI, 2015). Nessa mistura de referências tão díspares é que se constitui esse "ethos-alternativo" do Baixo Augusta, o qual mantem uma relação conflituosa com as lógicas mercadológicas e a cultura de massas em formas de incorporação e resistência.

Tal característica alude a algo que parece motivar esse "ethos": um desejo por se diferenciar e construir identidades singulares, as quais, ainda que se tornem modismos e sejam apropriadas pela cultura de massas, são de maneira dinâmica reelaboradas por esses grupos modificando-se novamente e deixando de lado certas tendências, apropriando-se de novas, e muitas vezes, ressignificando tendências antigas no intuito de se diferenciar da cultura hegemônica ao criar novos e múltiplos sentidos ao que provém do massivo, performatizando seus corpos e identidades. Estas sobreposições de diferentes estilos presentes nas formas de se vestir 
e até mesmo nas atitudes podem ser vistas em muitos frequentadores da região.

E desse modo é possível perceber que o mercado de moda formado nos arredores da região do Baixo Augusta se favorece dessas mesmas características e mesclas, buscando abastecer desejos e tentando segmentá-los em nichos de mercado. Uma dinâmica das lógicas de produção mercadológicas construídas ao se moldarem constantemente através de estratégias de marketing para melhor atender seu público, renovando estratégias e em diálogo com as apropriações táticas dos usuários num constante e conflituoso funcionamento dos processos culturais e de consumo ligados às culturas juvenis e urbanas ${ }^{6}$.

Essas características se mostram mais explícitas ao observarmos as galerias/lojas que vendem uma variedade de roupas/acessórios e artigos de decoração com referências vintage, retrô, vanguardista, clássica e moderna, mesclando todos esses referenciais que compõe os estilos desses consumidores/frequentadores. Outro ponto referencial são os restaurantes e food trucks especializados em comidas de diferentes origens do mundo, sempre com um aspecto gourmet que agrega valor monetário ao mercado e distintivo ao consumidor.

Por outro lado, ainda que os grupos alternativos que consomem esse mercado construído para atender seus diversos estilos de vida façam uso desses serviços e produtos, eles não absorvem e assumem completamente essa espécie de "molde" alternativo fabricado. Ainda que os mercados se armem de estratégias e constantes mudanças para se adaptarem e adequarem produtos e serviços destinados a esses consumidores, tais grupos reforçam suas características "alternativas" dando novos usos e apropriando-se de diferentes maneiras daquilo que lhes é oferecido, tentando fugir e burlar modelos padronizados do que seja "alternativo" seja

$6 \mathrm{Um}$ aspecto a ser explorado é o fato de estes jovens frequentadores serem também atores dos mercados de moda e de música desta localidade, onde as divisões estanques entre e produção e recepção precisam ser redimensionadas e reconceituadas. Jovens empreendedores da cultura ("trendys" ou "lançadores de tendências") (GARCIA CANCLINI et al, 2012), em várias cidades globais do mundo, são atores de circuitos alternativos nos quais têm protagonismo no lançamento de modas e estilos, sendo produtores e receptores em diferentes momentos. 
na música, na moda, nos hábitos de consumo ou nos estilos de vida assumidos.

Uma jovem frequentadora da região nos contou que não se vê como "alternativa" pois percebe que o mercado tenta construir um estilo de vida alternativo a partir da segmentação da música indie, padronizada para ser vendida como um gênero musical. Pode-se observar que as constantes estratégias mercadológicas de tentar enquadrar tais grupos são nítidas a alguns jovens, acarretando em táticas por parte daqueles que têm consciência destes processos em constantes negociações e articulações de ambos os lados.

Outros jovens abordados na pesquisa de campo também não se intitularam como alternativos, apesar de terem um estilo de vida não hegemônico e se enquadrarem em muitas das definições daquilo que se pode entender como um "ethos-alternativo" do Baixo Augusta. Ao não se definirem neste rótulo usam sempre da mesma justificativa: a convicção de que isso seria um estilo de vida moldado pelo mercado, perdendo assim seu prestígio, legitimação e distinção.

Entretanto, vários jovens que circulam pela região se intitulam como alternativos. Ignoram ou relevam as tentativas do mercado em padronizá-los e visam apenas as características pelas quais se querem constituir, seja na intenção de criar identidades distintas dos padrões hegemônicos, seja pelo simples fato de absorverem referências de diferentes estilos/ conceitos/tendências e agregá-las em seus estilos de vida (materializado em sua estética de moda e consumo musical), tendo como critério seus gostos pessoais e compartilhados.

\section{Considerações finais}

As narrativas destes jovens aliadas à observação do campo nos ajudam a compreender os sentidos esboçados por esta categoria identitária do "alternativo" como algo feito na tessitura de elementos hegemônicos, massivos, mercadológicos e também identitários e subjetivos, onde jovens usam a categoria "alternativo" (tanto os que dizem ser como os que negam esta categoria) como um modo de buscar construir estilos 
de vida que se querem críticos e com alto grau de performatividade via estetização do corpo, da vida, das experiências e dos afetos. Ora, sentidos políticos aí se esboçam nestas formas de consumo e de construção de identidades (ROCHA, 2012), em narrativas juvenis que constroem alguns sentidos para suas trajetórias e do que querem e mostram ser.

García Canclini (2010) sugere que as noções de resistência muitas vezes são esvaziadas de sentido ou empobrecidas quando se localizam em dicotomias fixas e excludentes como resistência versus domesticação, dada a multiplicidade de comportamentos que surgem buscando alternativas. Torna-se importante, assim, interrogar sobre os sentidos do político e da resistência em tempos em que mudanças e formas alternativas de viver e agir disjuntivas se encontram difusas em formas variadas de atuação. Na relação múltipla, reflexiva e dinâmica com que os jovens lidam com as várias modalidades de mídia são constituídos novos grupos subculturais ou alternativos que têm nuances e contradições internas diversas, sendo impossível reduzi-los a uma só narrativa de "integração ao sistema" ou de, contrariamente, "resistência" unívoca.

As negociações interculturais tornam-se uma das bases que contribuem para a formação de agrupamentos na contemporaneidade. Janotti Jr. (2003) propõe pensar a socialidade como parte do processo de produção de sentidos de grupos/sujeitos e suas interações, nas quais estão presentes também as territorialidades e os imaginários envolvidos nas comunidades de sentido. Pensando as socialidades construídas pelos grupos "alternativos" no Baixo Augusta, vale lembrar que existe uma constante troca de referências, conceitos e estilos. Tais trocas podem ser observadas, por exemplo, nas mesclas de diferentes gêneros musicais que estes jovens passam a consumir, frequentando ambientes ligados a gêneros bastante distintos, em misturas de pop e versões mais próximas do indie. Estas mesclas manifestam-se em suas características identitárias, projetando-se tanto na estética proporcionada pela moda quanto nas atitudes e hábitos presentes em seus estilos de vida e impulsionadas pelo consumo musical. Nos usos e apropriações desse constante fluxo 
de diferentes referências identitárias, é que se criam diferentes estilos por meio de hibridismos e ressignificações.

Por esta razão é que buscamos refletir sobre as maneiras pelas quais os grupos juvenis sinalizam formas de socialidade e maneiras de estar juntos, criando maneiras outras de usar e dar sentidos à cidade, edificar identidades e pertencimentos em táticas que podem ter sentidos políticos na medida em que criam outras formas de convivência, de consumo e de existência.

\section{Referências}

BASTOS, B. F. Construindo identidades, espaços e sentidos: o consumo cotidiano na cidade de São Paulo, um olhar sobre a Rua Augusta. 2016. Dissertação (Mestrado em Comunicação). Programa de Pós-Graduação em Comunicação e Práticas do Consumo. ESPM, São Paulo, 2016.

BOURDIEU, P. A Distinção - Crítica Social do Julgamento. Porto Alegre: Zouk, 2007. CERTEAU, M. A invenção do cotidiano - Artes de fazer. Petrópolis: Vozes, 1994.

ESCOSTEGUY, A. C. Cartografias dos estudos culturais: uma versão latino-americana. Belo Horizonte: Autêntica, 2001.

FEATHERSTONE, M. Cultura de consumo e pós-modernismo. São Paulo: Studio Nobel, 1995.

FEIXA, C. De jóvenes, bandas y tribus - antropología de la juventud. Barcelona: Editorial Ariel, 1996.

FREIRE FILHO, J. Das subculturas às pós-subculturas juvenis: música, estilo e ativismo político. Contemporânea - Revista de Comunicação. v.3, n.1, 2005.

FREIRE FILHO, J. Reinvenções da resistência juvenil: estudos culturais e micro-politicas do cotidiano. Rio de Janeiro: Ed. Mauad, 2007.

GARCÍA CANCLINI, N. ¿De qué hablamos cuando hablamos de resistencia? Estudios Visuales. Ensayo, teoría y crítica de la cultura visual y el arte contemporáneo. CENDEAC, n.7, p. 16-37. 2010.

GARCIA CANCLINI, N. et al. (Orgs.). Jóvenes, culturas urbanas y redes digitales. Madrid/Barcelona: Fund. Telefónica/Ariel, 2012.

GIDDENS, A. Modernidade e identidade. Rio de Janeiro: Zahar, 2002.

HAESBAERT, R. Territórios alternativos. São Paulo/Rio de Janeiro: Contexto/Ed.UFF, 2002. 
HALL, S. Quem Precisa da Identidade? In: SILVA, T. T. (Org.) Identidade e diferença: a perspectiva dos estudos culturais. Petrópolis: Vozes, 2000.

HALL, S.; JEFFERSON, T. (Orgs.). Resistance through rituals: youth subcultures in post-war britain. London: Routledge, 1993.

HEBDIGE, D. Subcultura: el significado del estilo. Barcelona: Paidós Ibérica, 2004.

HERSCHMANN, M. Cenas, circuitos e territorialidades sônico-musicias. In: JANOTTI JR, J.; SÁ, S.P. (orgs.). Cenas musicais. Guararema/SP: Ed. Anadarco, 2013. p. 41-56 HERSCHMANN, M. (org.) Nas bordas e fora do mainstream musical: novas tendências da música independente no início do século XXI. São Paulo: Ed. Letras e Cores, 2011.

JANOTTI JR, J. Mídia, cultura juvenil e rock and roll: comunidades, tribos e grupamentos urbanos. In: CONGRESSO BRASILEIRO DE CIÊNCIAS DA COMUNICAÇÃO, 2003. Belo Horizonte. Anais... Belo Horizonte, 2003.

JANOTTI JR, J.; SÁ, S.P. (Orgs.). Cenas musicais. Guararema/SP: Ed. Anadarco, 2013. MAGNANI, J. G. De perto e de dentro: notas para uma etnografia urbana. Revista Brasileira de Ciências Sociais - ANPOCS, v. 17. n. 49. 2002.

MARTIN-BARBERO, J. Dos Meios as Mediações. Rio de Janeiro: Editora UFRJ, 2009.

NUNES, M. R. Memória, consumo e memes de afeto nas cenas cosplay e furry. Revista Contracampo, v. 35, n.1, p. 142-162, 2016.

PEREIRA, Simone Luci; BORELLI, Silvia Helena. Música alternativa na Vila Madalena: práticas musicais juvenis na cidade. Revista Fronteiras - Estudos Midiáticos, v. 17, n. 3, p. 281-289, 2015.

PERUZZO, C. Aproximações entre comunicação popular e comunitária e a imprensa alternativa no Brasil na era do ciberespaço". In: CONGRESSO BRASILEIRO DE CIÊNCIAS DA COMUNICAÇÃO, 2008. Natal. Anais... Natal, 2008.

PETERSON, R.; KERN, R. Changing highbrow taste: from snob to omnivore. American Sociological Review. v. 61. n.5. p. 900-907. 1996.

ROCHA, R. M. Juventudes, comunicação e consumo: visibilidade social e práticas narrativas. In: BARBOSA, L. (Org.). Juventudes e gerações no Brasil contemporâneo. Porto Alegre: Sulina, 2012.

ROLNIK, R. História Urbana: História na cidade? In: FERNANDES, A.; GOMES, M. A. (Orgs.). Cidade e História: modernização das cidades brasileiras nos séculos XIX e XX. Salvador: Ed. UFBA, 1992.

STRAW, W. Systems of articulation, logics of change: communities and scenes in popular music. Cultural Studies. v. 5, n. 3, p. 368-388. 1991.

THORNTON, S. Club Cultures: Music, Media and Subcultural Capital. Cambridge: Polity Press, 1995.

VELHO, G. Antropologia urbana: encontro de tradições e novas perspectivas. Sociologia: Problemas e Práticas, n. 59, p. 11-18, 2009.

WILLIAMS, R. Marxismo e Literatura. Rio de Janeiro: Zahar Editores, 1979. 


\section{Sobre os autores}

Simone Luci Pereira - Graduada em História (bacharelado e licenciatura) (1994), Mestre em História Social (1998), Doutora em Ciências Sociais - Antropologia (2004) pela Pontifícia Universidade Católica de São Paulo. Professora e Pesquisadora do Programa de Pós-Graduação em Comunicação e Cultura Midiática da Universidade Paulista - UNIP, São Paulo, SP.

Vitor Pontes - Mestrando no Programa de Pós-Graduação em Comunicação e Cultura Midiática da Universidade Paulista - UNIP, São Paulo, SP.

Data de submissão: 29/1 1/2016

Data de aceite: 03/06/2017 